\title{
JÓZEF MARIA BOCHEŃSKI'S FORMAL ANALYSIS OF THE PRIMA VIA FROM 1953
}

\author{
MAREK PORWOLIK \\ https:/ / orcid.org/0000-0002-8091-7446 \\ Cardinal Stefan Wyszynski University in Warsaw \\ Department of Philosophy \\ Warsaw \\ Poland \\ m.porwolik@uksw.edu.pl
}

\begin{abstract}
Article info
CDD: 200.1

Keywords

J.M. Bocheński

St. Thomas Aquinas

prima via; Logic
\end{abstract}

Received: 16.07.2021; Revised: 13.09.2021; Accepted: 17.09.2021

https://doi.org/10.1590/0100-6045.2021.V44N4.MP

Abstract: J.M. Bocheński (1902-1995) together with J. Salamucha, B. Sobociński, and J.F. Drewnowski formed the so-called Cracow Circle in the 30 s of the previous century. Its main aim was to utilize contemporary logic in theology and philosophy of God. The first work in this area was Salamucha's formal analysis of the prima via, published in 1934. The article was reviewed by Bocheński, who provided a number of remarks concerning Salamucha's analysis. At that time he did not decide to conduct a holistic research into the prima via. That was done by him only at the end of his life as part of the logical analysis of the quinque viae. This paper aims at presenting Bocheński's unpublished formal analysis of the prima via from 1953 and proving that it constitutes a valuable completion of his published formal analyses, which come from the 1980s and 1990s. Above all, they provide a more insightful analysis of the notion of movement in the prima via, as well as the form of axiom expressing the lack of regress into infinity. In the formalizations of 1953 there are also interesting analyses concerning the ancestral closure of three-argument relations. 


\section{Introduction}

The known complete formal analyses of the quinque viae from St. Thomas Aquinas' Summa Theologiae, conducted by Fr. Józef Maria Bocheński (1902-1995) can be grouped into three versions. What connects them is the same form of a logical commentary. The versions are as follows:

I Bocheński (1989a), (1993b), (2000).

II Bocheński (1989b). (1993a).

III Bocheński (2003).

Those versions focus on the article Die fün Wege (1989a) and the book Gottes Dasein und Wesen. Logische Studien zur Summa Theologiae I, qq. 2-11 (2003). The book was published after Bocheński's death and contains numerous corrections, which were introduced by its editors, and which had not been authorized by Bocheński. For that reason, the formalizations included in the manuscripts of the book constitute a separate version of the analysis of the five ways.

Those texts come from the last years of Bocheński's life. In that period he returned to the ideas that inspired the socalled Cracow Circle. It was formed at the beginning of 1934, and it is considered to be a branch of the Lvov-Warsaw School. ${ }^{1}$ Its aim was to introduce the contemporary achievements of logic into Catholic philosophy and theology. ${ }^{2}$ Apart from Bocheński, the Circle consisted of Fr.

\footnotetext{
${ }^{1}$ Cf. Bocheński (1988, 1995); Woleński (2013); Murawski (2015); Tkaczyk (2017).

2 The papers and discussions from that meeting, which concerned Catholic philosophy and theology, were published in the year 1937 in issue 15 of the journal Studia Gnesnensia, which was titled: Myśl katolicka wobec logiki współczesnej (Catholic mind in relation to modem logic).
} 
Jan Salamucha (1903-1944), Jan Drewnowski (1886-1978), and Bolesław Sobociński (1906-1980). The activity of the Circle ceased with the outbreak of the Second World War.

The first partial logical analyses of the five ways (to be precise, of the first way) was conducted by Bocheński much earlier and incorporated into the review of Salamucha's work titled Dowód ex motu na istnienie Boga (The Proof ,ex motu” for the Existence of God. Logical Analysis of St. Thomas' Arguments). ${ }^{3}$ Although, according to Bocheński, those analyses might have been used to formalize Aquinas' text, he refrained from conducting such a formalization. In his later formalizations, from the 1980s and 1990s, Bocheński does not mention anything about him conducting a formal analysis of Aquinas' text after the Circle finished its activity. However, it turned out that there are unpublished formal analyses of the quinque viae, which he conducted in the 1950s. Those of them that concern the first way seem to be the most advanced and they have the form of a typescript of an article being prepared for publication. The other analyses appear in the form of less or more accurate notes. The aim of this paper is to critically present that material in the context of Bocheński's later analyses of the quinque viae. ${ }^{4}$ Bocheński was an outstanding expert in logic. The materials discussed here present him also as a scholar who applies formal methods in the analysis of logical problems.

\footnotetext{
${ }^{3}$ Cf. Salamucha (1934); Bocheński (1935).

${ }^{4}$ Bocheński's studies concerning the particular formalizations of Aquinas' ways can be found in the following publications: Nieznański (2006); Porwolik (2011a, 2020, 2011b, 2013b).
} 


\section{Sources}

The source text can be found in the manuscript of an unpublished set of Bocheński's works, which he titled Papers. ${ }^{5}$ It contains over 76 volumes, grouped into the following six series: 1-10 Philosophica; 11-25 Logica; 20-40 Marxistica; 41-55 Polonia; 56-75 1972 ss; 76ss Parva volumina. The substantial portion of Papers consists of articles, notes, and lectures. Some of them are preliminary versions of papers that were published earlier, so they are of great historical significance. The part devoted to logic is arranged in the following way: 11. 1934-71 A-C; 12. 1934-71 D-H; 13. 1934-71 I-L; 14. 1934-71 M-Q; 15. 1934-71 R-S; 16. 1934-71 T-Z; 17. Notre Dame 1955/6; 18. Denkmethoden; 19. History of Logic 1934-71; 20. Aristotle 1934-71.

In volume 11, number 15 in the table of contents reads: "(Bóg) Prima via 53" ("(God) Prima via 53"). The last number points to the year 1953, which also appears on some pages of the studied material. It seems to encompass the following six texts:

\section{Prima Via;}

2. Handwritten drafts of formalizations of the ways from two to five;

3. An untitled text concerning the Prima Via;

4. Remarques logiques et methodologiques sur la Prima Via;

5. A handwritten formalization of the Prima Via;

6. Analyse mathematica-logiques de la Prima Via de S. Thomas.

\footnotetext{
${ }^{5}$ Photocopies of a part of Papers have been surrendered to the Department of Logic and Methodology of Sciences at the Faculty of Christian Philosophy, Cardinal Stefan Wyszynski University in Warsaw, by Fr. Dr Korneliusz Policki from Fribourg.
} 
The above texts are listed in the order, in which they are found in the studied manuscript. They concern mainly St. Thomas Aquinas' prima via. Only in part 2 do we find very sketchy drafts of formalizations of the remaining ways. However, in that part, there are no detailed analyses or polemic remarks. The last text, which can be found in part 6 , seems to be the final version of a logical commentary concerning the prima via. At the end of it, there is Bocheński's signature, and the text looks like a paper prepared for publication. Unfortunately, it has never been published. The other texts referring to the prima via, present here, are not the preliminary versions of the text from part 6 . It seems that Bocheński wrote the mentioned analyses from scratch, not only correcting the earlier versions of the text, but also editing it again. Obviously, when it comes to the content of particular analyses, it is possible to notice new remarks, as well as modifications of the earlier analyses. What is interesting is the fact that these analyses differ remarkably from those that Bocheński published in the 1980s and the 1990s. Moreover, certain remarks from those unpublished texts are a valuable complement to the later works, and in some places they even appear to be subtler.

Because of the residual character of the analyses concerning the ways from two to five in the materials from 1953 we will focus on those of them that concern the first way. In order to do that we will present the final version of its formalization, as well as the most important remarks provided by Bocheński. The basic text for us will be text 6 from the manuscript. 


\section{The remarks, observations, and commentaries provided by Bocheński}

The investigations done by Bocheński in Analyse mathematicalogiques de la Prima Via de S. Thomas are grouped by him in the following parts:

a) Preliminary remarks

Bocheński reminds us that the first formalization of the prima via was conducted by Fr. Jan Salamucha. His analysis concerned the argumentation from St. Thomas Aquinas' Summa contra Gentiles. Since in Bocheński's opinion that analysis was far from satisfactory for numerous reasons, he wants to conduct it again, but this time on the basis of the Summa Theologiae. He intends to conduct an analysis that will be purely logical. He wishes to refrain from discussions concerning acceptance of the ontological assumptions of Aquinas, and instead only wants to point to them. In Bocheński's views, that seems important because it happens that St. Thomas is believed to accept certain assumptions, which in fact he never did. An example given by Bocheński is the claim ascribed to Aquinas, according to which each infinite sequence has its first term. ${ }^{6}$

The above-mentioned preliminary remarks already reveal the polemic nature of the presented analyses of Bocheński. The polemics concern Salamucha's views, but above all,

${ }^{6}$ Bocheński refers to Russell, who writes about Aquinas' quinque viae in the following way: "Or take again the arguments professing to prove the existence of God. All these, except the one from teleology in lifeless things, depend upon the supposed impossibility of a series having no first term. Every mathematician knows that there is no such impossibility; the series of negative integers ending with minus one is an instance to the contrary." Cf.: $(1955,453)$.

Manuscrito - Rev. Int. Fil. Campinas, v. 44, n. 4, pp. 169-201, Oct.-Dec. 2021. 
Russell's. In the 1950s, when the text we present was being created, and when Russell was still alive, a polemic with his view was invaluable. Nowadays, when the way of interpreting Aquinas usually differs from that presented in $A$ History of Western Philosophy, devoting too much attention to Russell's views in a work on the quinque viae seems to be unnecessary.

b) The formal structure of movement according to Aquinas

Bocheński's remarks concerning the notion of movement, which is the key notion in the first way, are extremely important for his further analyses. Object $y$ that is moving, moves from potency to act in relation to something, a certain attribute $z$. This situation can be expressed in symbols as $B(y, z)$. Then, the fact that $y$ is moving can be expressed in the following way: $\exists B(y, z)$ or $y \in D^{\prime} B$ (y belongs to the domain of relations $B$ ). Since we are talking about moving from potency to act, symbolically expressed as $P(y, z)$, as a result we obtain: $\underset{y, z}{\exists}[B(y, z) \wedge P(y, z)]$.

To St. Thomas, for every $y$ that is moving, there exists something that moves it (a certain $x$ ). Thus, here we deal with a new relation: $M(x, y)$. When we are considering this relation, we need to take into account also the thing towards which $y$ is moving (a certain $z$ ). Now, to Bocheński, the relation of moving presented by Aquinas is a relation with three arguments: a certain $x$ (a mover or a motor), $y$ (the object moved), and $z$ (the aspect, under which $y$ is moved). The relation between $z$ and $x$ is expressed symbolically as $F$. 
These binary relations constitute components of the threeargument relation of moving $T$. $^{7}$

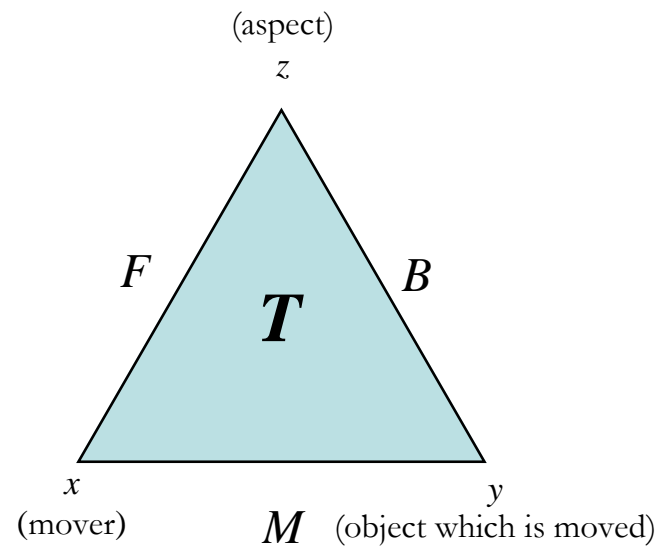

Fig. 1. The three-argument relation of moving $T$

In the case when the mover is a created being (the mover is moved to move), it must be moved by another mover in order for it to cause movement. In that situation, it is necessary to have another mover $(t)$, which will move $x$ to move $y$ towards $z$.

${ }^{7}$ Because of the fact that Bocheński uses the same letters for different two-argument and three-argument relations, in the figures we use the bold font for the latter ones.

Manuscrito - Rev. Int. Fil. Campinas, v. 44, n. 4, pp. 169-201, Oct.-Dec. 2021. 


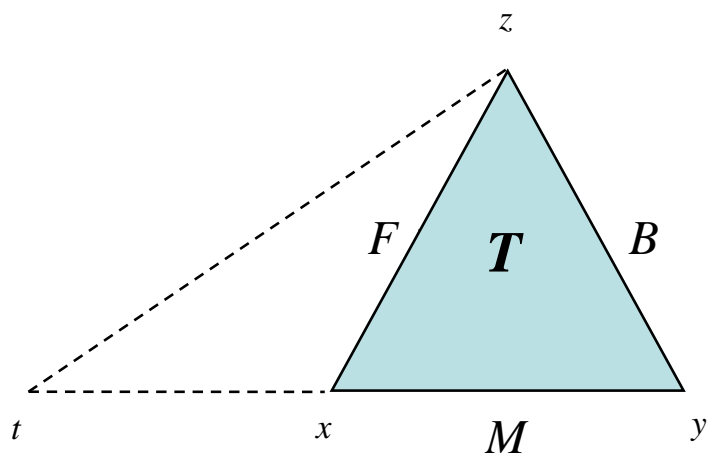

Fig. 2. The case of a moved mover

Here, Bocheński asks a question whether that new threeargument relation (among $t, x$, and $z$ ) is identical with relation $T$. His answer is negative. Even if the relation between $t$ and $x$ was identical with relation $M$, and the relation between $t$ and $z$ was identical with $F$, still the relation between $z$ and $x$ is clearly different from relation $B$ because it is not $x$ that is moving to act towards $z$, but it only makes $y$ move to act.

In the situation where a given mover is moved, we can consider some series of relations among subsequent moved movers, for instance, between $x_{1}, x_{2}, x_{3}$, and $x_{4}$. In Bocheński's opinion, there are two cases to consider here. In the first case, we assume that those relations are identical with the relation between $x_{4}$ and $y$. The other option is an assumption that they are different from it and expressed by relation $R$. 


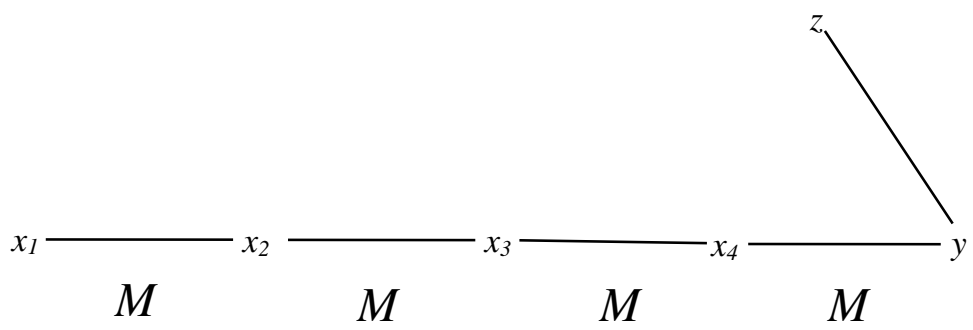

Fig. 3. A sequence of moved movers: case one

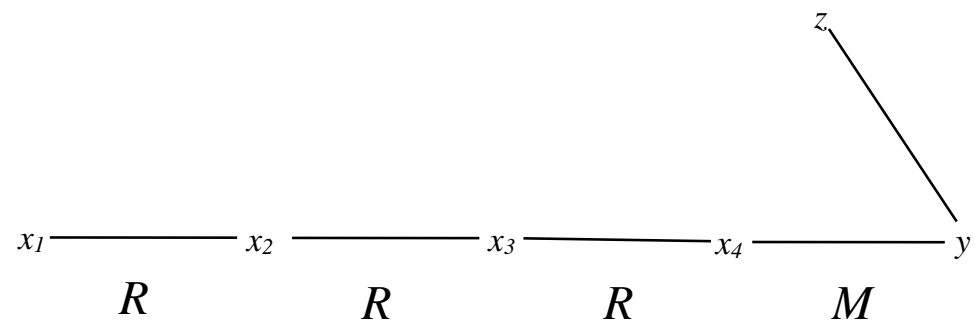

Fig. 4. A sequence of moved movers: case two

In the first case, we can assume that the three-argument relation among $x_{1}, y$ and $z$ can be split into the following three binary relations:

1) $M_{p o}$ (a strong ancestral closure of relation $M$ )

2) $B$

3) $F$.

Manuscrito - Rev. Int. Fil. Campinas, v. 44, n. 4, pp. 169-201, Oct.-Dec. 2021. 
In the second case, we have the following:

1) $R * ; M$ (a composition of a weak ancestral closure of relation $R$ and relation $M$ )

2) $B$

3) $F$.

Thus, the prima via can be analyzed in two ways. Bocheński believes that for the sake of ontological reasons, the latter approach is more adequate, but it appears that St. Thomas himself chose the former approach, which is simpler with regard to the formalization of the argumentation as such. When making those remarks, Bocheński writes that in his analyses he wants to choose the former approach. In fact, however, he chooses the latter one, and assumes that the relation that occurs between the subsequent moved movers is not $M$, but $R$.

Bocheński's analyses of movement presented above seem to be of great importance. First, because of the fact that apart from one and two-argument relations (which was the case in Salamucha's works), Bocheński uses also a three-argument relation. This way of interpreting Aquinas' text was repeated in Bocheński's later works, and even half a century later, it was still considered as innovative and invaluable (Nieznański 2006, 33). Second, the analyses of relations between elements in the sequence of movers seem to be important. In the subsequent parts of Bocheński's work they help him distinguish another three-argument relation that is used to describe those sequences.

c) Important aspects of Aquinas' argumentation

When it comes to the course of the proof, in the views of Bocheński, Aquinas deals with it as follows: since he notices 
that $\underset{y, z}{\exists} B(y, z)$, he assumes silently that

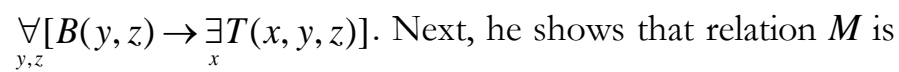
irreflexive. Those two theses allow us to confirm the existence of a sequence of objects connected with one another by means of relation $R$. The series created in such a way has the first element, not because of logic, but for the continuity of the ontological nature of relation $R$, which requires it to have such an element. Thus, St. Thomas argues that there exists the first element of relation $R_{p o}$, that is, the first mover that moves something else to move towards $z$, but which itself is not moved.

Those observations, in the opinion of Bocheński, may induce us to postulate an axiom. It is difficult to figure out exactly what Aquinas' axiom is. Russell supposed that Aquinas was proposing that, as a matter of logic, every sequence must necessarily have a first element, but this is almost certainly not Aquinas' axiom, since it is not only false but inconsistent with the Thomistic context. Salamucha proposed an alternative interpretation, attributing to Aquinas the assumption that there exists the first element of the sequence created by relation $R$, but not of all sequences. Therefore, if Salamucha's interpretation were correct, Aquinas would be advancing a purely an a priori argument. ${ }^{8}$

Thus, Bocheński claims that for those reasons two kinds of postulates arise:

1) The axiom mentioned above cannot be treated as a mathematical/logical thesis, but rather as a synthetic claim, based on the intuition concerning its content;

\footnotetext{
${ }^{8}$ Bocheński paid attention to that also in his review of Salamucha's article.
} 
2) It cannot be formulated in a way that exempts us from using the original empirical thesis.

The above-mentioned analyses constitute the next part of Bocheński's polemic with Salamucha and Russell.

d) Relation $M *$

When analyzing the relation of a weak ancestral closure, Bocheński refers to the contents of Bertrand Russell and Alfred North Whitehead's Principia Mathematica (PM). ${ }^{9}$ In fact, he refers to the claims included in that book also in other places, for instance, when he describes the foundations of inferencing in the formalization of Aquinas' argumentation. It is a constant benchmark for him. Nevertheless, the problem is that the theory of ancestral closures, which is described in that work, only concerns twoargument relations. For that reason, Bocheński tries to make it more general and use it in the case of three-argument relations that he is considering. He splits them into twoargument relations. Thus, in any three-argument relation $R(x, y, z)$, we can define:

$$
\begin{aligned}
& R_{1} \stackrel{d f}{=}\{(x, y): \underset{z}{\exists} R(x, y, z)\}, \\
& R_{2} \stackrel{d f}{=}\{(y, z): \underset{x}{\exists} R(x, y, z)\}, \\
& R_{3} \stackrel{d f}{=}\{(z, x): \underset{y}{\exists} R(x, y, z)\} .
\end{aligned}
$$

We can illustrate that by means of the following figure:

\footnotetext{
${ }^{9} \mathrm{Cf} .(P M, * 90)$. The same abbreviation $(P M)$ is used by Bocheński himself.
} 


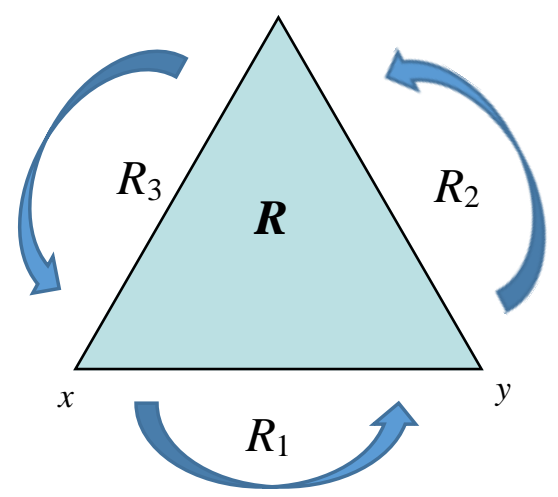

Fig. 5. Two-argument components of three-argument relation $R$

In such a case, in the opinion of Bocheński, relation $R(x, y, z)$ can be analyzed, using relations $R_{1}$ and $R_{2}$ in the following way:

(R) $R(x, y, z) \leftrightarrow \exists_{y}\left[R_{1}(x, y) \wedge R_{2}(y, z)\right]$.

Let $M$ be a three-argument relation that is supposed to form sequences of movers. Its two-argument component $M_{2}$ is included in relation $T$, namely, it is a converse of relation $T_{3}$. 


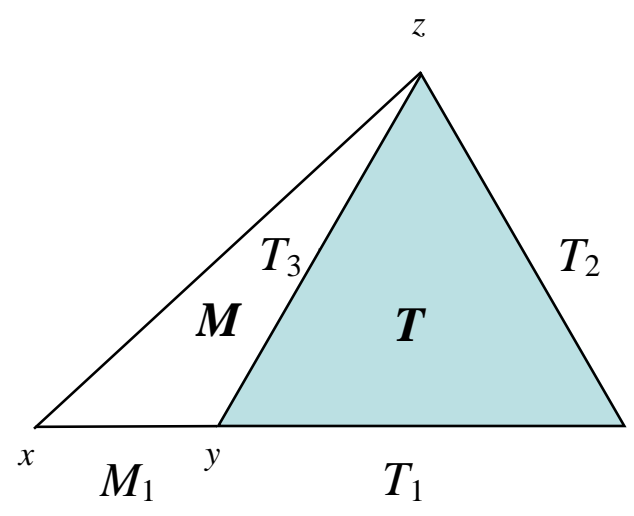

Fig. 6. Relations $M$ and $T$

Then, he can write the following:

(M)

$$
M(x, y, z) \leftrightarrow \underset{y}{\exists}\left[M_{1}(x, y) \wedge T_{3}(y, z)\right] .
$$

In that case, $M_{*}$, which is understood as a weak ancestral closure of relation $M$, can be described as follows:

$(M *) \quad M_{*}(x, y, z) \stackrel{d f}{=}{ }_{y}\left[M_{1^{*}}(x, y) \wedge T_{3}(y, z)\right]$,

which means:

$$
\begin{aligned}
M_{*}(x, y, z) \leftrightarrow \exists_{y}\left\{\left[M_{1}(x, x) \wedge T_{3}(x, z)\right] \vee\right. & \\
\quad\left[M_{1}(x, y) \wedge T_{3}(y, z)\right] & \left.\vee\left[M_{1}^{2}(x, y) \wedge T_{3}(y, z)\right] \vee \ldots\right\} .
\end{aligned}
$$

Bocheński emphasizes that here it is not enough to have relation $M_{1 p o}$ of the strong ancestral closure of relation $M_{1}$. We can think of a situation where the first mover directly makes itself move a certain object under a certain aspect: $M_{1}(x, x) \wedge T_{3}(x, z)$. Besides, he notices that actually it is relation $M$, and not $T$, that creates the series considered by St. Thomas.

However, Bocheński's proposition presented above requires some improvements. Variable $y$ on one side of 
equivalence $(R)$ is bound, while on the other side it is not. Here, omitting the existential quantifier that binds variable $y$ does not solve any of the problems found. It is sufficient to consider a counterexample of relation $R=$ $\{(1,2,4),(5,2,3)\}$. Then, we obtain $\sim R(1,2,3)$ and $\exists\left[R_{1}(1, y) \wedge R_{2}(y, 3)\right]$, or when we omit the small quantifier: $R_{1}(1,2) \wedge R_{2}(2,3)$. As a consequence, we need to reject dependencies $(M)$ and $(M *)$, assumed by Bocheński. Let us note that when three-argument relation $R$ has at least one two-element domain, its projections $R_{1}, R_{2}$, and $R_{3}$ do not determine that relation unequivocally. In that case, it is impossible to identify a general dependency between the relation and its projections - a dependency that would take the form of an equivalence, as Bocheński wishes. However, it is not necessary to modify relation $(R)$ and dependency $(\boldsymbol{M})$ proposed by Bocheński. It is enough to focus directly on dependency $(M *)$. In order to modify that dependency, first I propose to define the (weak) ancestral closure of threeargument relation for the sake of the selected variable present in it in the following way:

$$
\begin{aligned}
& \left(R *_{z}\right) \quad R_{*_{z}}(x, y, z) \stackrel{d f}{=} \underset{x^{\prime}}{\exists}\left[R_{1^{*}}\left(x, x^{\prime}\right) \wedge R\left(x^{\prime}, y, z\right)\right], \\
& \left(R_{*_{y}}\right) \quad R_{*_{y}}(x, y, z) \stackrel{d f}{\underset{z^{\prime}}{\exists}}\left[R_{3^{*}}\left(z, z^{\prime}\right) \wedge R\left(x, y, z^{\prime}\right)\right], \\
& \left(R *_{x}\right) \quad R_{*_{x}}(x, y, z) \stackrel{d f}{=} y_{y^{\prime}}\left[R_{2^{*}}\left(y, y^{\prime}\right) \wedge R\left(x, y^{\prime}, z\right)\right] .
\end{aligned}
$$

Then, instead of dependency $\left(M^{*}\right)$ we can assume the following:

$$
\left(M *^{\prime}\right) \quad M_{*}(x, y, z) \stackrel{d f}{=} \underset{x^{\prime}}{\exists}\left[M_{1^{*}}\left(x, x^{\prime}\right) \wedge M\left(x^{\prime}, y, z\right)\right] .
$$

Apart from that, as we can notice, accepting the possibility that $M_{1}(x, x)$ for certain object $x$, because of the 
irreflexive nature of relation $T_{1}$, excludes the situation where $M_{1}=T_{1}$, which is the first interpretation of the prima via presented by Bocheński in $\mathrm{b}$ ).

The situation described by Bocheński can be illustrated by us in the following way:

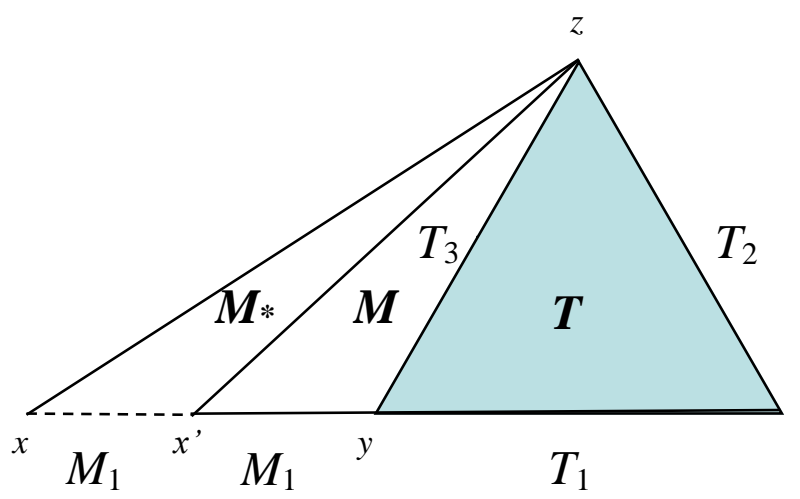

Fig. 7. Relations $M$ and $M *$

To sum up this part of Bocheński's analyses we can say that he showed an interesting idea concerning the description of ancestral closures of three-argument relations, despite the fact that his proposal requires some modifications. Moreover, it is worth to notice the distinction of another three-argument relation, marked as $M$, used in the analyses apart from relation $T$. In his analyses of the prima via from the 80 s and 90s, Bocheński distinguishes only one three-argument relation concerning movement.

e) Formal analysis

Bocheński emphasizes that the main course of the proof in the prima via is progressive. First, the respective axioms are 
listed, and second, what follows is an unbroken chain of conclusions, leading to final conclusion (11). At every step of his formalization, Bocheński refers to the claims from the Principia Mathematica. Since that work discusses only the theory of two-argument relations, he sometimes points to those claims merely as counterparts of the ones that he uses. For the sake of the handwritten remarks, added by Bocheński to the analyzed text, we will provide two versions of the formalization. They concern axiom five and describe the understanding of the first mover. The lines that were corrected with Bocheński's handwriting are marked with "'". It appears that they are more consistent with Aquinas' text because they postulate that the first mover should not be moved under a certain aspect $(z)$, but that it should not be moved (directly or indirectly) to move something under that aspect. $^{10}$

$$
\begin{aligned}
& \text { A1. } \underset{x, y, z}{\forall}[A(x, z) \wedge P(y, z) \rightarrow x \neq y] \\
& \text { A2. } \underset{x, y, z}{\forall}[T(x, y, z) \rightarrow A(x, z) \wedge P(y, z)] \\
& \text { A3. } \underset{y}{\forall}[K(y) \rightarrow \underset{x, z}{\exists} T(x, y, z)] \\
& \text { A4. } \underset{y}{\exists} K(y) \\
& \text { A5. } \underset{x, z}{\forall}\{\exists[y \\
& \text { A5'. } \\
& \underset{x, z}{\forall}\left\{\underset{y}{\exists}[T(x, y, y, z) \wedge x \neq y] \rightarrow \underset{t}{\exists}\left[M_{*}(t, x, z) \wedge \underset{u}{\forall} \sim M_{*}(u, t, z)\right]\right\}
\end{aligned}
$$

${ }^{10}$ Abbreviations: $K(x):=x$ is moving; $A(x, z):=x$ is in act under aspect $z ; P(x, z):=x$ is in potency under aspect $z ; T(x, y, z):=y$ is moved by $x$ under aspect $z ; M(x, y, z):=y$ is moved by $x$ to moving under aspect $z ; M_{*}$ is the ancestral closure of relation $M$. 
1. $\underset{x, y, z}{\forall}[T(x, y, z) \rightarrow x \neq y] \quad * 10.3$; A1; A2

2. $T(x, y, z) \rightarrow x \neq y \quad * 10.1 ; 1$

3. $T(x, y, z) \rightarrow[T(x, y, z) \wedge x \neq y] \quad * 4.7 ; 2$

4. $\underset{x, z}{\forall}\{T(x, y, z) \rightarrow[T(x, y, z) \wedge x \neq y]\} \quad * 11.11 ; 3$

5. $\underset{x, z}{\exists} T(x, y, z) \rightarrow \underset{x, z}{\exists}[T(x, y, z) \wedge x \neq y] \quad * 11.34 ; 4$

6. $K(y) \rightarrow \underset{x, z}{\exists} T(x, y, z) \quad * 10.1 ; \mathrm{A} 3$

7. $K(y) \rightarrow \underset{x, z}{\exists}[T(x, y, z) \wedge x \neq y] \quad$ Syll.; 5; 6

8. $\underset{y}{\forall}\{K(y) \rightarrow \underset{x, z}{\exists}[T(x, y, z) \wedge x \neq y]\} \quad * 10.11 ; 7$

9. $\underset{y x, z}{\exists}[T(x, y, z) \wedge x \neq y]\} \quad * 10.28$; 8; A4

10. $\underset{x, z y}{\exists}[T(x, y, z) \wedge x \neq y]\} \quad * 11.24 ; * 11.04 ; 9$

11. $\underset{x, z}{\exists} \exists\left[M_{*}(t, x, z) \wedge \underset{u}{\forall} \sim T(u, t, z)\right] \quad * 11.34 ; * 1.1 ; \mathrm{A} 5 ; 10$

$\left(11^{\prime} . \underset{x, z}{\exists}\left[M_{*}(t, x, z) \wedge \underset{u}{\forall} \sim M_{*}(u, t, z)\right] * 11.34 ; * 1.1 ; \mathrm{A} 5^{\prime} ; 10\right)$

The language of formalization given above has been modernized. Bocheński uses the notation taken from the Principia Mathematica. He lists axioms separately from the subsequent steps of deduction.

Taking into account our modifications suggested in d), which are based on symbols concerning the splitting of a three-argument relation into two-argument relations, we can modify the above formalization, using formula $(M *$ '), and including the possibility, mentioned by Bocheński, that there exists such an object which is in relation $M_{1}$ with itself. Now, axiom five from Bocheński's formalization can take the following form: 
A5"

$\underset{x, z}{\forall}\{\exists[T(x, y, z) \wedge x \neq y] \rightarrow$

$\left.\underset{t}{\exists}\left[M_{*}(t, x, z) \wedge \underset{u}{\forall}\left(u \neq t \rightarrow \sim M_{*}(u, t, z)\right)\right]\right\}$.

Then, verse 11 from the formalization will assume the following form:

(11") $\underset{x, z}{\exists} \exists\left[M_{*}(t, x, z) \wedge \underset{u}{\forall}\left(u \neq t \rightarrow \sim M_{*}(u, t, z)\right)\right]$.

The consequent in that axiom determines the way of understanding the first mover in St. Thomas' argumentation $(P)$ as follows:

$(P) \underset{t}{\forall}\left\{P(t) \leftrightarrow \underset{x, z}{\exists}\left[M_{*}(t, x, z) \wedge \underset{u}{\forall}\left(u \neq t \rightarrow \sim M_{*}(u, t, z)\right]\right\}\right.$.

Defining the first mover in the above-mentioned way fails to guarantee its oneness. Besides, we notice that with a specific $z$ the mover is a minimal element of a certain two-argument relation, although not necessarily its first element. Also, it is worth noticing that predicate $M$ does not appear directly in the formalization, but that predicate $M_{*}$ is defined with its use.

f) Axioms A1, A2, and A3

To Bocheński, those axioms constitute the foundation for the Thomistic analysis of movement. He discusses each of them separately.

Axiom A3 says that if something is moving, there is something that makes the thing that is moved to move from potency to act. The axiom does not state directly that the mover is separated from the object moved. St. Thomas himself does not pay attention to that either, although, in Bocheński's opinion, nothing can be proven here without it. 
It seems that, to him, replacing that axiom with the following pair of axioms would be closer to the text:

$$
\begin{aligned}
& \text { A3a. } \underset{y}{\forall}[K(y) \rightarrow \underset{x}{\exists} R(x, y)], \\
& \text { A3b. } \underset{x, y}{\forall}[R(x, y) \rightarrow \underset{z}{\exists} T(x, y, z)],
\end{aligned}
$$

where $R$ is interpreted as a two-argument relation, describing movement ("movet"). That measure would extend the proof slightly. Although axiom A3 itself has the form of an implication, Bocheński claims that St. Thomas ponders equivalence here. Thus, if we assume only an implication here, it is so merely because it will suffice for the proof.

Axiom A2 is based on the notions of act and potency. Bocheński notices that it would be tempting to define potency in the following way: $P \stackrel{d f}{=} \sim A$. In that case, axiom A1 would be unnecessary because its equivalent could be obtained from $P M$. Unfortunately, in his views, such a definition fails to fit the Thomistic idea of potency, which differs from the negation of act.

Thus, to Bocheński, axioms A1, A2, and A3 are formulated as a result of an ontological analysis of movement, unlike axiom 4, which is an empirical thesis.

In this and two subsequent parts of his work, in which Bocheński discusses the specific axioms, we can notice a tendency to place them among those that are either ontological or empirical assumptions. A similar thing can be found in Bocheński's analyses published later. In those later works he calls them premises, and not axioms. In Gottes Dasein und Wesen, on the basis of the analysis of premises used in questions 2-13 of the Summa, Bocheński distinguishes those of them that to him can constitute a preliminary axiomatics of the theory of the Absolute.

g) Axiom A4 
In St. Thomas' theory, that axiom is accepted on the basis of sensory experience. Bocheński notices that, in that case, "movetur" has the meaning of $K$, and not that of $T$. The reason for that is the wish to avoid a syntactic nonsense. Salamucha refuses to accept A4 as an axiom, but to him, it is a postulate that guarantees the real nature of the first mover. Bocheński emphasizes that there is a temptation to omit this axiom. He justifies that fact in the following way.

As it has already been mentioned, the sentence "hic autem non est procedere in infinitum" was interpreted by some scholars (e.g. Russell) as St. Thomas' claim in the Summa that every sequence $R$ always has its first term, so:

\section{$\exists ! \vec{B}^{\prime} R$.}

In Bocheński's views, not only is it unacceptable as a mathematical/logical thesis, but in that way, the context, in which "hic" (here) is said, is overlooked. However, if we assume that it is a certain special sequence, that is:

$\exists ! \vec{B}^{\prime} M_{1}$,

then we go along the same way that was chosen by Salamucha. In that situation, we can prove the existence of the first mover without referring to axiom A4.

Here, Bocheński provides the following reasoning that refers to the theses and definitions from PM:
(1) $\exists ! \vec{B}^{\prime} M_{1}$ (axiom)
(2) $\exists ! C^{\prime} M_{1}-O^{\prime} M_{1}$ *93.103
(3) $\exists ! D^{\prime} M_{1} \cup \sigma^{\prime} M_{1}-\sigma^{\prime} M_{1}$
$* 33.16$
(4) $\exists ! D^{\prime} M_{1}-\sigma^{\prime} M_{1}$ $* 22.9$
(5) $\underset{x}{\exists}\left(x \in D^{\prime} M_{1} \wedge x \in-O^{\prime} M_{1}\right)$
$* 24.03$ 


$$
\begin{array}{ll}
\text { (6) } \underset{x}{\exists}\left[\underset{y}{\exists} M_{1}(x, y) \wedge x \sim \mathrm{C}^{\prime} M_{1}\right] & * 33.13 ; * 22.35 \\
\text { (7) } \underset{x}{\exists}\left[\underset{y}{\exists} M_{1}(x, y) \wedge \sim \underset{z}{\exists} M_{1}(z, x)\right] & * 33.131
\end{array}
$$

In Bocheński's opinion, that way of interpreting the prima via contradicts the spirit of its author for it becomes an a priori argument. Besides, he believes that it also casts a light on the Principia Mathematica, which appears to be strongly Platonistic in its unstated assumptions. The last remark of Bocheński seems to be insufficiently justified by his analyses. When it comes to the analyses from this part of his work, again they reveal their polemic character.

\section{h) Axiom A5}

In the next part of his work, Bocheński analyzes the first version of axiom five, marked by us as $\mathrm{A} 5$.

A5. $\underset{x, z}{\forall}\left\{\underset{y}{\exists}[T(x, y, z) \wedge x \neq y] \rightarrow \underset{t}{\exists}\left[M_{*}(t, x, z) \wedge \underset{u}{\forall} \sim T(u, t, z)\right]\right\}$

This axiom can be expressed in the following way: for every $x$ and $z$, if there exists $y$, such that $T(x, y, z)$ and $x \neq y$, there exists $t$, such that $M_{*}(t, y, z)$, and for every $u$ it is not true that $T(u, t, z)$.

To Bocheński, that axiom has the following consequences:

(1) It does not say that $\underset{t}{\exists} \forall_{x, z} M_{*}(t, x, z)$. Thus, we can imagine a situation where there are a few first movers. Bocheński notices that St. Thomas devoted a separate question in his Summa to the problem of the uniqueness of God.

(2) It does not exclude the possibility of the existence of a few first movers that influence the second mover. 
(3) The expression $\underset{u}{\forall} \sim T(u, t, z)$ that appears in this axiom only says that the first mover is first in relation to $z$. Thus, it could be moved under another aspect $r$ $(r \neq z)$.

When it comes to the justification of the acceptance of that axiom, in Bocheński's opinion, it is based neither on logic, nor on the system from PM. Bocheński claims that it is the result of an ontological analysis of relation $T$. It imposes the existence of the first term.

As we have mentioned before, in the same text, Bocheński provides another (hand-written) version of that axiom:

A5'. $\left.\underset{x, z}{\forall} \underset{y}{\exists}[T(x, y, z) \wedge x \neq y] \rightarrow \underset{t}{\exists}\left[M_{*}(t, x, z) \wedge \underset{u}{\forall} \sim M_{*}(u, t, z)\right]\right\}$.

Because of its important role, it is worth providing here its versions from the other texts:

text 1:

$$
\underset{x, y}{\exists}\left[M_{p o}(x, y) \wedge \underset{z}{\forall} \sim M_{p o}(z, x)\right],
$$

text 3:

$$
\underset{x, y, z}{\exists} R(x, y, z) \rightarrow \underset{t}{\exists}\left[\underset{u}{\forall} R_{1}(t, u) \wedge \sim \underset{v}{\exists} R_{1}(u, t)\right],
$$

text 4:

$$
\underset{x, y}{\forall} M(x, y) \rightarrow \underset{z}{\exists}\left[R_{1 p o}(z, x) \wedge \underset{t}{\forall} \sim R_{1 p o}(t, z)\right],
$$

text 5:

$$
\begin{aligned}
\underset{x, y}{\exists}\{M(x, y) \wedge x \neq y \rightarrow \\
\left.\quad[\underset{z}{\forall} \sim M(z, x)] \vee\left[\underset{t}{\exists} M_{*}(t, x) \wedge \underset{u}{\forall} \sim M_{p o}(u, t)\right]\right\} .
\end{aligned}
$$

The multiple versions of axiom five are the result of changes in the interpretation of Aquinas' text, and they prove the importance of this axiom to Bocheński in his 
formalization of the prima via. We need to notice that in texts $1,4,5$, and 6 this axiom postulates the existence of a minimal element of a given relation, while in text 3 , of the first element. Obviously, the form of the axiom in the particular versions was adjusted to the other axioms and symbols used in a given formalization.

\section{i) Aquinas' method of reasoning}

Bocheński emphasizes the deductive nature of the prima via. To him, St. Thomas, despite the common opinion, fails to explain certain phenomena by means of the First Mover, but he assumes axioms obtained from an experiment and ontological analysis and he infers from them the particular theses in a deductive way. The general schema is as follows:

(1) axiom A4 is expressed,

(2) thesis 8 is expressed,

(3) thesis 8 is proven,

(4) axiom A5 is expressed,

(5) conclusion 11 is proven.

It is possible to distinguish two proofs here: A5),

(a) the main proof for thesis 11 (because of $\mathrm{A} 4,8$, and

(b) the auxiliary proof for thesis 8 (because of A1, A2, and A3).

The proof for the main thesis is progressive (from premises to the conclusion), but the auxiliary proof is regressive (from the conclusion to premises). In the latter case, first, the conclusion is expressed, and then, where necessary, axioms are gradually introduced. 
In a way similar to the methods presented above Bocheński will discuss the five ways in his later analyses, reconstructing their argumentative structure.

j) Remarks concerning the applied logic

In Bocheński's view, in order to provide the formal reconstruction of the prima via, it is sufficient to study the first 11 chapters from $P M$. The only exception is the notion of ancestral relation $(R *)$, which is explained in chapter 90 .

Thus, the logical tools used here are very simple. The following notions are used: three-argument, two-argument, and one-argument functors, universal and existential quantifiers, and ancestral relations.

When it comes to the logical calculi used, sentential logic is applied only once, in order to prove thesis 7 . It is the rule of syllogism. Apart from that, in the inference a rule related to Darii was used, namely, the following rule: $\underset{x}{\forall}[f(x) \rightarrow g(x)] \rightarrow[\underset{x}{\exists} f(x) \rightarrow \underset{x}{\exists} g(x)]$ (thesis 5). The only reason that it is not the classical Darii form is the presence of complex variables. Therefore, according to Bocheński, the prima via exceeds the simple Aristotelian syllogistic.

Similar conclusions are drawn by Bocheński in his later analyses of the five ways. While analyzing questions 3-11 besides question 2 (where the ways can also be found), he will show that in the latter questions the sufficient tool for identifying inferences is Aristotelian syllogistic.

\section{The significance of Bocheński's analyses from 1953}

After the presentation of the analyses conducted by Bocheński, it is time to draw some conclusions. First, they concern the evolution of views presented in the analyzed 
texts, and second, their relation to the views found in Bocheński's works that were published in the last years of his life.

When it comes to changes observed in particular texts from 1953, the basic difference among them concerns the form of axiom A5. Firstly, the differences concern St. Thomas' understanding of movement in the prima via, and the relations used to express it. In text 1 , we only have at most two-argument predicates describing movement, and in the remaining texts, which concern that way, the most important role is played by three-argument predicates: moving something under a certain aspect, or moving something to move something else. The analysis of those relations influences the understanding of St. Thomas' view on the impossibility of regress into infinity. Bocheński uses the notion of ancestral closure to describe that. Depending on the accepted view on movement, axiom 5 takes different forms in the studied material. That, in turn, influences the formalization itself. Thus, the analysis of the notion of movement in Aquinas' prima via, as well as the form of the axiom that describes the lack of regress into infinity, appear to be the key elements in the discussed analyses. As we have shown it above, Bocheński's analyses concerning ancestral closures of three-argument relations, as well as the form of axiom 5 require certain modifications.

When we compare those versions, we notice that, apart from minor changes and intrusions, our attention is caught by changes in the justification of accepting axioms A1, A2, and A3. They describe the foundations of the theory of movement in the prima via. In texts 1 and 3, Bocheński writes about phenomenological and eidetic analyses and intuition, while in his last text he writes about an ontological analysis. It is interesting that in his works he fails to describe axiom A1 in detail, but instead he focuses on axioms A2 and A3 from the list of axioms mentioned here. 
Another question is comparing the analyzed texts from 1953 with those known to us, which come from the 1980s and 1990s. The most important conclusion seems to be the fact that Bocheński fails to include the earlier texts in his later analyses. Obviously, the method of analysis is very similar. Here, the texts from the end of the $20^{\text {th }}$ century seem to surpass the earlier ones in the extent of the analyses and their order (listing the abbreviations and rules of reasoning used, providing the full Latin version of the analyzed text, and distinguishing definitions from premises). The remarks concerning Salamucha's role in the formalization of the first way, distinguishing three relations describing movement (one, two, and three-argument), and the analyses concerning the character of the particular axioms (premises) are elements present in the research from 1953, which can be also found in Bocheński's other texts, published a few decades later. However, in some points, the earlier analyses seem not only to complete the later analyses, but also to surpass them. Above all, they provide a more insightful analysis of the notion of movement in the prima via, as well as the form of axiom expressing the lack of regress into infinity. In Bocheński's later texts mentioned above, we only have the following formula: $\sim\left(M A D_{*} \operatorname{cinf}\right) \rightarrow \underset{x}{\exists} M(x)$, which is difficult to understand! In the list of abbreviations we have only: $\operatorname{Inf}(x)-x$ est infinitus, $M(x)-x$ est primum movens; $R_{*}$ cInf - the series formed by $R$ is infinite. Unfortunately, nowhere in his later texts does Bocheński explain the symbols used there (we can only guess that the dependency provided is related to ancestral closure, not to mention the fact that it is unknown how to understand it in the case of a three-argument relation) or specifies what it means that $x$ is primum movens. He tries to explain it in his commentary and to show the minimal element of a specific series, but he fails to include it in the formalization. It is included implicite in the 
formalization from 1953. In those analyses, Bocheński talks directly about the ancestral closure, and he precisely describes how they can be generalized in the case of splitting two-argument relations into three-argument ones. He also specifies what relations describing movement that closure concerns. In his later works, Bocheński omits those analyses. Additionally, he fails to discuss the three-argument relation of moving something to move something else under a specific aspect, restricting himself to considering only one three-argument relation: of moving something under a specific aspect. Bocheński's remarks from the 1953 text can be an invaluable supplement to the later analyses that are well known today. His superficial treatment of the prima via in the later texts can be a consequence of Bocheński's change of approach to the first way. In the text from 1953 he states that the aim of his analyses is not criticizing, but becoming acquainted with that argumentation. In his later texts, Bocheński openly praises the second way, at the same time expressing disapproval of the other ways. It is particularly visible in the case of the fourth way, where his analyses seem to be conducted in a manner that leads to proving the worthlessness of that argumentation. Moreover, they are very superficial and inadvertent at times.

When we compare the analyses from the two periods, we may also focus on secondary issues. Here, the dispute with Bertrand Russell's way of interpreting the prima via is important. To Bocheński, it changes that argumentation into an a priori proof. Apart from that, from the historical point of view, it is interesting to observe how the way of describing inferences at particular stages of formalization changed. In his 1953 works, Bocheński refers to the theses from PM. All the introduced mathematical/logical notions and theses come from that work. Therefore, writing about the ancestral closure of a three-argument relation was a challenge for Bocheński, because that notion is absent from PM. In his 
analyses from that period, he also used symbols from that work. In the particular texts from the 1980s and 1990s, we can observe him gradually abandoning that notation in favor of the contemporary symbols.

It is possible that Bocheński's analyses of the five ways from 1953 will never be published, thus becoming only archival materials. Nowadays, their polemic value has been weakened. For sure, apart from their historical value, they are important because of the fact that they contain invaluable remarks concerning Aquinas' understanding of movement in his prima via, as well as ancestral closures of three-argument relations. To me, in those two questions they are much better than those of Bocheński's analyses that are commonly known these days.

\section{References}

BOCHEŃSKI, J. M. "Bibliographie Critique n. 935". Bulletin Thomiste, 12(IV/8), pp. 601-603, 1935.

BOCHEŃSKI, J. M. "Die fünf Wege". Freiburger Zeitschrift für Philosophie und Theologie, 36(3), pp. 235-265, 1989a. Repr. in J. M. Bocheński (1993b); J. M. Bocheński (2000).

BOCHEŃSKI, J. M. "Koło Krakowskie". Kwartalnik Filozoficzny, 23(1), pp. 23-31, 1995.

BOCHEŃSKI, J. M. "Koło Krakowskie". Życie Literackie, 45, p. 12, 1987. Repr. in J. M. Bocheński (1988), J. M. Bocheński (1995).

BOCHEŃSKI, J. M. "Pięć dróg". In J. M. Bocheński (1993b), pp. 469-503.

BOCHEŃSKI, J. M. "The Cracow Circle". In K. Szaniawski (ed.) (1988), pp. 9-18. 
BOCHEŃSKI, J. M. "The Five Ways". In A. Garcia de la Sienra (ed.) (2000), pp. 61-92.

BOCHEŃSKI, J. M. Gottes Dasein und Wesen. Logische Studien zur Summa Theologiae I, qq. 2-11. München: Philosophia Verlag, 2003.

BOCHEŃSKI, J. M. Gottes Dasein und Wesen. Mathematischlogische Studien zur Summa Theologiae I, qq. 2-13. Freiburg: a maniscript, 1989b.

BOCHEŃSKI, J. M. Gottes Dasein und Wesen. Mathematischlogische Studien zur Summa Theologiae I, qq. 2-13. Freiburg: a manuscript in the Polish language, Transl. by J. M. Bocheński (no title page), 1993a.

BOCHEŃSKI, J. M. Logika i filozofia. Wybórpism. Warszawa: Wydawnictwo Naukowe PWN, 1993b.

BOCHEŃSKI, J. M. Papers. a manuscript.

BROŻEK, A., STADLER, F., WOLEŃSKI, J., TKACZYK, M. The Significance of the Lvov-Warsaw School in the European Culture. Wien: Springer, 2017.

BROŻEK, B., OLSZEWSKI, A., HOHOL, M., Logic in Theology. Kraków: Copernicus Center Press, $2013 \mathrm{a}$.

GARCIA DE LA SIENRA, A. The Rationality of Theism. Amsterdam-Atlanta: Rodopi, 2000.

MURAWSKI, M. "Cracow Circle and Its Philosophy of Logic and Mathematics". Axiomathes, 25, pp. 359-376, 2015.

NIEZNAŃSKI, E. "Prima via św. Tomasza w formalizacji Ojca Bocheńskiego". Studia Philosophiae Christianae, 42(1), pp. 27-35, 2006.

PIECHOWICZ, J. Logika i teologia. Katowice: Księgarnia św. Jacka, 2011a. 
PORWOLIK, M. "„Piąta droga” św. Tomasza z Akwinu w formalizacjach J.M. Bocheńskiego i P. Weingartnera". Roczniki Filozoficzne, 61(3), pp. 77-99, 2013b.

PORWOLIK, M. Formalisation of the Argument Ex Causa Efficientis Presented by Fr. Bocheński. In B. Brożek, A. Olszewski, M. Hohol (eds.) (2013a), pp. 159-177.

PORWOLIK, M. Formalizacje argumentu ex causa efficientis $w$ wykonaniu o. Bocheńskiego. In J. Piechowicz (ed.) (2011a), pp. 26-39. Repr. in B. Brożek, A. Olszewski, M. Hohol (eds.) (2013a).

PORWOLIK, M. "Józefa Marii Bocheńskiego formalizacje trzeciej drogi św. Tomasza z Akwinu". Przeglad Tomistyczny, 26, pp. 295-323, 2020.

PORWOLIK, M. "Ojca Bocheńskiego formalizacje "czwartej drogi" św. Tomasza z Akwinu". Logos $i$ Ethos, 31(2), pp. 109-130, 2011b.

RUSSELL, B. A History of Western Philosophy. London: George Allen \& Unwin Ltd, 1955.

RUSSELL, B. A History of Western Philosophy. New York: Simon\&Schuster 1945. Repr. in B. Russell (1955).

SALAMUCHA, J. "Dowód ex motu na istnienie Boga". Collectanea Theologica, 53, pp. 53-92, 1934. Repr. in J. Salamucha (1958); J. Salamucha (2003).

SALAMUCHA, J. Knowledge and Faith. Amsterdam-New York: Rodopi, 2003.

SALAMUCHA, J. "The Proof ex motu for the Existence of God. Logical Analysis of St. Thomas' Arguments". The New Scholasticism, 32(3), pp. 327-372, 1958. 
SALAMUCHA, J. "The Proof ex motu for the Existence of God. Logical Analysis of St. Thomas Aquinas' Arguments". In J. Salamucha (2003), pp. 97-135.

SZANIAWSKI, K. The Vienna Circle and the Lvov-Warsaw School. Dordrecht: Kluwert Academic Publishers, 1988.

TKACZYK, M. Cracow Circle: Theology in the Lvov-Warsaw School. In A. Brożek, F. Stadler, J. Woleński (ed.) (2017), pp. 173-188.

WOLEŃSKI, J. "Józef M. Bocheński and the Cracow Circle". Studies in East European Thought, 65(1-2), pp. 515, 2013.

$(c c)$ BY 